\title{
NAVORSING AAN ONS UNIVERSITEITE
}

Die taak van 'n universiteit is tweeledig, nivorsing en dosering, of verwerwing en oordrag van kennis. Dit is duidelik dat die moderne maatskappy 'n groot waarde heg aan die verwerwing en besit van kennis as daarop gelet word dat die staat bereid is om jaarliks miljoene ponde te spandeer aan inrigtings wat hierdie doel dien. Uit 'n oogpunt van verwerwing en oordraging van kennis is ons universiteite op die huidige tydstip seker nog die belangrikste van hierdie inrigtings. 'n Belangrike vraag wat hom nou egter voordoen, is wat die waarde is wat aan kennis as sodanig geheg word. Op hierdie vraag is daar seker verskillende antwoorde moontlik. Alle antwoorde sal m.i. gegrond moet 
word op een van die volgende twee beginsels. Die eerste is dat kennis waarde het omdat dit ons die werklikheid laat begryp, omdat dit ons dus waarheid gee. Kennis het dus waarde juis omdat dit kennis is en dit vind sy waarde in homself. Die soeker na kennis wat hom op hierdie standpunt stel, word tot sy soeke beweeg deurdat hy 'n liefde het vir die sake waaroor hy kennis verlang.

Die tweede beginsel is dat kennis waarde het omdat kennis die mens mag verleen, in die besonder mag oor die sake wat geken word. Hier word natuurlik implisiet ook veronderstel dan kennis waaragtig moet wees, aangesien valse kennis eintlik geen kennis is nie en geen mag kan gee nie, maar die beweegrede tot die verkryging van kennis is hier die begeerte om mag te verwerf.

Iemand mag teëwerp dat kennis ook verwerf kan word met die doel om te dien, wat denkbaar is by mense soos medici, ingenieurs en ander wetenskaplikes. Die wil tot kennis ontstaan hier baie duidelik uit 'n begeerte om die dinge wat geken moet word diensbaar te stel aan iets anders en is dus in wese ' $n$ begeerte tot mag oor die dinge wat geken moet word. Die medikus wil lewens red en is daarom geinteresseerd in bakterieë. Sy wens is dus nie soseer om bakterieë te bestudeer slegs om sy weetdrif te bevredig nie, ma:ar omdat hy mag oor hulle wil hê om hulle diensbaar te stel of te vernietig.

Die wetenskap het sy oorsprong by mense wat kennis ter wille van die kennis gesoek het, wat 'n liefde vir die wêreld en die dinge om hulle gehad het en besiel was met 'n begeerte om die waarheid aangaande hierdie dinge te wete te kom. Hulle ondersoekinge het hulle gedcen slegs om die vreugde wat die ontdekking van nuwe waarhede hulle gebring het. Heraclitus en die Ioniese filosowe van wie die eerste stoot tot wetenskaplike ondersoek gekom het, was mense wat in hierdie liefde hulle krag tot ondersoeking gevind het, wat kennis ter wille van die waarheid gesoek het.

Maar kennis gee ook mag en stadigaan, met die ontwikkeling van die wetenskap, het 'n nuwe soort wetenskaplike ondersoeker ontstaan by wie dit nie meer soseer om die hondjie as om die halsbandjie gaan nie. Waar dit by vroeër ondersoekers meer gegaan het om grondliggende beginsels, gaan dit by die strewers na mag om prakties bruikbare kennis. Die magsbegeerte is beliggaam in die industrie, oorlogstegniek en regeringswese en is in die wysbegeerte ingedra deur die pragmatisme. 
Solank die mag wat wetenskaplike kennis gee aangewend word tot die totstandbrenging van die goeie, kan mens daar nog vrede mee hê, maar as die strewe na mag ' $n$ doel in homself word, as dit 'n magstrewe ter wille van mag self word, kan daar slegs kwaad uit voortkom, nie slegs vir die mens as sodanig nie, maar ook vir die lewende wetenskap as 'n steeds voorskrydende soeke na waarheid.

Die gevaar wat vir die wetenskaplike ondersoek in die magsbeginsel geleë is, bestaan daarin dat die nadruk nie meer val op onderliggende beginsels nie maar op wetenskaplike tegniek. Sowat sestig jaar gelede het Clerk Maxwell sy teorie oor elektrisiteit gepubliseer. Vandag nog is hierdie teorie voldoende vir alledaagse gebruike van elektrisiteit soos by kragstasis, radio's en al die ander dinge wat hierdie vorm van energie nodig het vir hulle funksionering. Tog het by die nuwere ontwikkeinge in die Fisika, by name relatiwiteit en kwantummeganika, geblyk dat Maxwell se teorie onvoldoende is. Dit doen egter niks af aan die bruikbaarheid van hierdie teorie nie. Die persoon wat slegs waarde heg aan wetenskaplike tegniek is tevrede met die teorie omdat dit resultate gee en aan sy doel van bruikbaarheid beantwoord. Daardeur neem hy 'n ander houding aan as die werklike wetenskaplike ondersoeker. Sy houding is nie die versigtige, soekende, redelike houding van die werklike wetenskaplike wat nooit voorgee dat hy die hele waarheid weet nie, maar is gewoonlik 'n houding van bewuste mag en hoogmoedige sekerheid. Die gevolge van so 'n houding kan verreikend wees vir 'n land en volk, soos gebeurtenisse in die wêreld oorvloedig aandui. Dit is egter 'n vraagstuk waarop hier nie ingegaan sal word nie.

Wetenskaplike ontdekkinge is gemaak ter wille van die ontdekkings self en nie altyd ter wille van hulle "nut" nie. Toe Faraday sy ondersoekinge i.v.m. elektrisiteit gedoen het, het hy geen vergesigte gehad met groot kragstasies, elektriese ligte, radio's, beheerde projektiele ens. in die verskiet nie. Hy het elementêre verskynsels i.v.m. elektrisiteit ondersoek omdat dit hom geïnteresseer het. Sy resultate is deur Maxwell in matematiese vorm gegiet wat d.m.v. suiwer teoretiese konstruksies die bestaan van elektro-magnetiese golwe voorspel het. Hertz het daarna die bestaan van die golwe eksperimenteel aangetoon. Daarna het Marconi die weg oopgemaak vir inspanning van die elektromagnetiese golwe vir kommersiële doeleindes met die uitvinding van die radio. Sover nagegaan kan word, het nie een van Faraday, Maxwell of 
Hertz belangstelling gehad vir die praktiese bruikbaarheid van hulle ontdekkinge nie.

By baie ondersoekinge in die natuur en matematiese wetenskappe in die verlede en vandag nog was toepasbaarheid en bruikbaarheid van resultate slegs 'n newe-oorweging. Van die grootste ontdekkings het voortgevloei uit oorwegings wat niks met bruikbaarheid of "nut" te doen het nie, ontdekkings wat later van die grootste belang vir die toegpaste wetenskap (en tegniek) geblyk te wees het.

Die soek na kennis ter wille van mag is uiteindelik skadelik vir die verwerwing van nuwe kennis. Die belangrikste resultate het partykeer uit die skynbaar triviaalste ondersoekinge voortgevloei. Sonder die werk van Van Leeuwenhoek wat bakterieë ondersoek het slegs omdat dit hom interesseer het, sou Pasteur se ontdekkinge miskien nie moontlik gewees het nie. Deurdat Riemann hom in die grondslae van die Meetkunde geïnteresseer het, met geen enkele bygedagte aan „bruikbaarheid" of materiële wins nie, het hy aan Einstein die wiskunde vir sy relatiwiteitsteorie verskaf wat weer gehelp het om kernkrag te ontsluit. As 'n wetenskaplike slegs voorbedag is op onmiddellik bruikbare resultate, sal hy waarskynlik werklik belangrike ondersoekingswerk te triviaal ag om daaraan aandag te gee, sodat die wetenskaplike ondersoek uiteindelik sal stagneer en in „trial and error"-ploetery sal degenereer. Kennis ter wille vinn kennis blyk ook die beginsel te wees waarby die strewer na mag uiteindelik die meeste sal baat.

Hoe beïnvloed hierdie magsbeginsel by die waardering van kennis ons universiteite? Terwyl die universiteit by uitstek die plek behoort te wees waar die dosente uit liefde vir hulle vak navorsing kan doen vanweë die rustige akademiese sfeer, die afwesigheid van oormatige finansiële sorge en die geroep om bruikbare ondersoek-resultate van die kant van industrieë, die regering of die publiek, vind ons dat die magsbeginsel 'n groot en somtyds oorheersende rol by die opstel van curri. cula en navorsingsprogramme speel. 'n Vak soos Wiskunde word dikwels so gedoseer dat dit weinig meer as 'n hulpvak vir die ingenieurswese, Fisika en Skeikunde is wat vakke is met praktiese waarde. Vakke soos Grieks en Latyn word gedoseer omdat hulle nodig is by die opleiding van predikante en word eintlik maar geduld omdat hulle tradisioneel in 'n universiteit hoort. Die Wysbegeerte word al lank skuins aangekyk en beskou as ,akademiese" gepraat. Meer en meer word die universiteite opleidingskolleges vir een of ander professie. Steeds meer 
en meer word in vakke by die opleiding van huishoudkundiges, aptekers, onderwysers, ingenieurs en verpleegsters die nadruk gelê op die praktiese. Bowendien word kursusse ingestel wat veel beter sou tuishoort in 'n tegniese kollege vanweë hulle uitgesproke nadruk op die aanleer van wetenskaplike tegniek. Ook van owerheidsweë is daar 'n begunstiging van vakke wat hulle leen vir die bruikbare te bespeur. Die genoemde magsbeginsel kom by professionele opleiding daarin tot uiting dat die nadruk dikwels val op die student se voorbereiding vir 'n geldelike verdienste.

Dat professionele opleiding uit die bose is, word geensins beweer nie. By die professionele opleiding aan 'n universiteit moet die nadruk egter altyd val op die wetenskaplike vorming van die student. Die groot geva:ar lê daarin dat hy slegs 'n resep-kennis opdoen sonder dat 'n ware wetenskaplike houding en 'n liefde vir die belangelose soeke na waarheid by hom gekweek word.

Daar word dikwels van bruikbare of "nuttige” kennis gepraat. Om die begrip „,nuttig" te definieer, is 'n moeilike taak. As 'n kennis van die geskiedenis die mens die huidige struktuur van die maatskappy waarin hy lewe en die verhoudings tussen volke beter laat begryp, is dit tog seker nuttig. As die Wysbegeerte die wetenskaplike insig gee in die beginsels waarop sy kennis berus, is dit ook nuttig. Tog is dit al beweer dat die geskiedenis as vak liewer nie in skole gedoseer moet word nie en dat dit slegs as vermaak saans by die kaggel gelees moet word. Per slot van rekening is alle kennis nuttig omdat alle kennis die mens iets omtrent die werklikheid leer en daarom die mens sy posisie in die geskape werklikheid beter laat verstaan.

As die skrywer daarin geslaag het om die leser met hom te laat saamstem dat ' $n$ oordrewe waardetoekenning aan die mag wat verworwe kennis die mens gee, 'n wesenlike gevaar inhou nie alleen vir 'n land en nasie nie, ma:ar vir die gesonde verloop van die wetenskaplike ondersoek self, dan sal die leser ook met die skrywer saamstem dat die universiteit die plek is waar die geleentheid bestaan en dit die verpligting is om belangelose wetenskaplike ondersoek slegs ter wille van die kennis self te bevorder.

Die grootste taak van die universiteit is m.i. dus om te verhoed dat wetenskaplike navorsing sal vervlak tot ' $n$ magstrewe. Alleen om hierdie rede rus daar 'n verpligting op elke dosent aan 'n universiteit om 
hom te wy aan ware wetenskaplike navorsing, om sodoende die tradisie van kennis ter wille van die liefde vir die waarheid voort te dra.

Die taak van 'n universiteit is egter ook die oordrag van kennis en nie slegs navorsing nie. Die oordrag van kennis is egter nie te skei van navorsing in al sy fasette van ontdekking van nuwe feite, herinterpretasie van nuwe en reeds bekende feite, waardering, skeppende kritiek en grondslae-ondersoek nie. Navorsing is natuurlik nie beperk tot die ontdekking van nuwe feite deur eksperimentele ondersoek, statistiese opnames, opgrawings ens. nie, alhoewel daar teenswoordig 'n sterk neiging is om dit as sodanig te beskou-wat miskien weer verband hou met die reeds genoemde magstrewe. Wat 'n veel groter gawe van oorspronklikheid vereis, is die vermoë om feite te korreleer en te interpreteer en om nuwe lig op onderlinge verbande te werp. Die goeie teoretiese fisikus is 'n veel seldsamer verskynsel as die goeie eksperimentele fiikus, en die interpretasie van statistiese gegewens vereis meer insig as die versameling daarvan. Die goeie dosent is dan ook 'n dosent met 'n eie siening op die leerstof, wat verbande kan aantoon en benadruk wat nie in leerboeke gegee word nie of waaroorheen ligtelik in handboeke gegaan word. Navorsing en doseerwerk is komplementêr en gaan hand aan hand. Nie alleen baat die dosering van 'n vak by die navorsing van die dosent nie, maar ook die omgekeerde geld. Geen navorsingswerk is die naam waardig as dit nie mondeling of deur publikasie weer meegedeel word aan ander nie, en deur mededeling aan belangstellende, intelligente mense word eie belangstelling en aktiwiteit weer geprikkel.

By gebrek aan navorsing moet stagnasie by die dosent intree.. Wat ' $\eta$ openbaring was dit nie vir die skrywer om die lesings aan te hoor van ' $n$ man wat self op die voorpunt van navorsing in sy vak gestaan het, om kennis te maak met die geesdrif waarmee hy sy vak benader het en die besieling wat van hom uitgegaan het nie. Hoe vergelyk dit met die dosent wat maar net dieselfde kan vertel wat in een of ander voorgeskrewe handboek staan?

Uiteindelik is dit ook deur navorsingswerk waardeur 'n universiteit hom laat ken in die buitewêreld. Die algemene publiek het miskien reeds die hoogste agting vir 'n universiteit as die studente maar goed op die sportveld presteer, maar die werklike diens wat 'n universiteit aan land en volk bewys en waarvoor hy deur die nageslag gedank sal word, is die aard en gehalte van die kennis wat hy versprei het. Maar 
ook big werkgewers, ernstig denkende mense en wetenskaplike inrigtings sal dit die gehalte van die afgelewerde produk wees wat die universiteit sy aansien sal gee.

Dat dit alles gesê moet word in 'n land wat hom aansluit by 'n 800 jaar oue Westerse universitêre tradisie, sal vir die leser miskien oorbodig lyk. Tog is dit die vraag in hoeverre hierdie ideaal van die tweeledige taak van die universiteit nagestreef word deur ons Afrikaanse universiteite; en dan is die antwoord nie te bemoedigend nie. Alle dosente aan universiteite sal dadelik toegee dat dit die taak van die universiteit is om kennis oor te dra en navorsingswerk te doen. Maar by enkele uitsonderinge is die instelling só dat doseerwerk absoluut die eerste plek inneem en navorsingswerk die tweede plek. As deur 'n oorlaaide program die tyd kortkom, dan is dit sonder uitsondering die navorsingswerk wat oorboord gaan-ás daar navorsingswerk gedoen word in die departement. Soos op die hoërskool is dit nog steeds die student wat in die middelpunt van die belangstelling van die dosent staan en nie die vak wat deur hom gedoseer word nie. Allerlei programme om lui studente te laat studeer, of om hulle sonder inspanning te laat studeer, en allerlei skoolse metodes word ingevoer om die student se weg makliker te makk. Daardeur word meer en meer tyd van die dosent in beslag geneem, en dit altyd maar ten koste van produktiewer werk. As die ideaal van die ware universiteit in ere gehou wil word, sal ook navorsing in die wetenskap in al sy vertakkinge weer sy regmatige aandeel van die dosente se belangstelling moet kry en nie beskou moet word as iets wat slegs af en toe in sy vrye tyd 'n bietjie aandag hoef te kry nie.

Miskien is dit vir 'n groot deel te danke aan die invloed van professionele opvoedkundiges in ons land dat die student se behoeftes steeds deurslaggewend is by oorweging van sake. Uit die aard van die Opvoedkunde as wetenskap, is dit die leerling en die student wat die middelpunt van die opvoedkundige se belangstelling vorm. Dit is dan begryplik dat die opvoedkundige ook wil hê dat die student die middelpunt van die fisikus se belangstelling moet wees, en nie meer die eienskappe van materie nie-dit wat die fisikus juis moet bestudeer. By die hoërskole is dit juis so dat die onderwyser se vakkennis, d.w.s. kennis i.v.m. die vakgebiede wat gedoseer word, betreklik laag aangeslaan word in vergelyking met sy kennis oor een of ander vertakking van die Opvoedkunde. So erg is dit dat heel weinig onderwysers 
eintlik die moeite wil doen om 'n magistergraad in sy bepaalde vak te neem, omdat dit hulle in die eerste plek nie finansieel betaal nie, geen goeie grond vir promosie is nie en, so beweer hulle, dit hulle nie sal help om hulle vak beter te doseer nie-waaruit die magsbeginsel by die verwerwing van kennis weer spreek.

Dat algemeen beweer word dat meer vakkennis as wat vereis word vir ' $n$ Baccalaureusgraad nie nodig is vir $n$ ' hoërskoolonderwyser nie, is beslis onrusbarend. Hoedat groter vakkennis nie kan meehelp by die onderrig van enige onderdeel van die vak nie, is onbegryplik. Hierdie oorbenadrukking van die Opvoedkunde en die posisie van die student is besig om van die hoërskole stadig deur te sypel na ons universiteite.

Ook van universiteitsowerheidsweë word dikwels gepraat oor navorsingswerk maar weinig gedoen om dit aan te moedig. By Europese universiteite is die eerste oorweging by die aanstelling van 'n dosent sy reeds gelewerde wetenskaplike prestasies op navorsingsgebied. Hoe dikwels word hier dosente aangestel wat nog nooit enige noemenswaardige publikasie gelewer het nie? Die gebruik om studente met slegs 'n Baccaleursgraad as juniorlektore en lektore aan te stel bloot omdat haastig iemand gevind moet word om die drukkende las van doseerwerk te verlig, is aan almal bekend. So 'n persoon het nog geen blyke gegee van bekwaamheid vir navorsingswerk nie en kom miskien ook nooit daaraan toe nie, maar word deur die loop van jare op grond van senioriteit en ander oorwegings tog bevorder.

Hieruit blyk al voldoende dat, alhoewel daar dikwels gepraat word oor navorsingswerk aan ons universiteite, die instelling van ons universiteitsowerhede so is dat dit navorsingswerk nie met krag bevorder nie. Geen wonder dat so langsamerhand daar van regeringsweë institute gestig word wat hierdie deel van die universiteit se werk oorneem nie. As op dié weg voortgegaan word, sal die universiteite ontaard in gewone kolleges.

Om die ideaal van die werklike universiteit te bevorder is dit in die eerste plek nodig om bekwame mense, met die nodige geesdrif en toewyding as dosente aan te stel, mense wat reeds blyke gegee het van hulle vermoë om navorsingswerk te doen en wat ook die liefde daarvoor het om daarmee voort te gaan. In die tweede plek moet aan hierdie mense die middele en die tyd gegun word om hulle werk te doen, ja moet daar gesorg word dat daar tyd en middele is. Liewer moet daar navorsingswerk geskied ten koste van doseerwerk as andersom. Alleen 
as ons universiteite hulle houding t.o.v. navorsingswerk radikaal verander, sal ons universiteite hulle naam werklik waardig wees en meer wees as verhoogde hoërskole.

In 'n artikel soos hierdie kan uiteraard alleen enkele aspekte van die probleem aangeraak word. Ongetwyfeld is daar ook ander faktore wat meespreek. As die skrywer daarin geslaag het om s.i. 'n dringende probleem na vore te bring, het ook die artikel in sy opset geslaag.

P.U. vir C.H.O.

H. J. SCHUTTE. 